\title{
Investigation of Physical Activity Levels of Physical Education and Sports School Students
}

\author{
Mehmet YILDIRIM ${ }^{1}$ \\ 'University of Yozgat Bozok, School of Physical Education and Sports, Yozgat, Turkey \\ Email:mehmet2682@hotmail.com
}

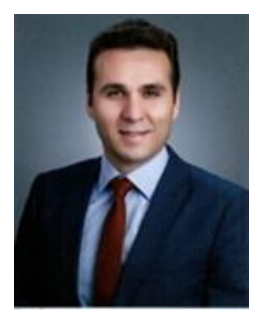

\begin{abstract}
The aim of this research is to determine the physical activity levels of physical education and sports school students and to examine the physical activity levels according to some demographic characteristics. The objective of the research is composed of 480 students who are studying different programs in Bozok University Physical Education and Sports School in 2017-2018 academic year. The sample of the research is composed of 300 students' determined random sampling method among the students studying in Bozok University Physical Education and Sports School in 2017-2018 academic year. Demographic information about the students in the survey was obtained with the personal information form and information about the level of participation in physical activity by the International Physical Activity Scale (Short form). Frequency, percentage, cross tables, Chi-Square and ANOVA tests were used in the analysis of the data. As a result of the analyzes; statistically significant differences were found between physical activity levels according to gender, body mass index, education department, sports branch and cigarette use variables $(\mathrm{p}<.05)$.
\end{abstract}

Keywords: Physical activity, University, Student.

Citation | Mehmet YILDIRIM (2018). Investigation of Physical Activity Levels of Physical Education and Sports School Students. Asian Journal of Education and Training, 4(4): 336-344.

History:

Received: 6 June 2018

Revised: 17 July 9018

Accepted: 20 August 2018

Published: 24 September 2018

Licensed: This work is licensed under a Creative Commons Attribution 3.0 License (c))

Publisher:Asian Online Journal Publishing Group
Funding: This study received no specific financial support

Competing Interests: The author declares that there are no conflicts of interests regarding the publication of this paper.

Transparency: The author confirms that the manuscript is an honest, accurate, and transparent account of the study was reported; that no vital features of the study have been omitted; and that any discrepancies from the study as planned have been explained.

Ethical: This study follows all ethical practices during writing

\section{Contents}

1. Introduction 


\section{Introduction}

Physical activity involves the activities, which are performed by using the muscles and joints in an energyconsuming way, increasing the heart and breath rates, and ending up with fatigue at various severities (Gür and Küçükoğlu, 1992). Alongside the sports activities, involving a part or whole of the motions of walking, running, jumping, swimming, cycling, crouching-rising, arm and leg movements, exercises, games, as well as the various activities being performed throughout our daily-lives are also acknowledged among the physical activities (Bek, 2008).

The physical activity of an individual or a group is classified according to the environment in which the same activity is performed. The common categories consist of the activities at work, home, and in the vicinity of the house, as well as the self-care, free-time, sports, or transportation (Burton and Turrell, 2000). Free-time physical activity involves all the activities, other than those being performed at work, and is divided into three: - Sports, game, fitness exercises, - Walking, cycling, climbing up the ladders, - Chores, recreational activities, garden works, car-washing, etc (Howley, 2001).

It is acknowledged by the authorities that, since the sedentary life-styles have reached to an ever-expanding tempo, the adverse bodily and psychological problems it causes have reached to worrisome levels. The people's worries regarding productivity loss and health increment the social cost. At this point, physical activity possesses both preventive, and healing effects on numerous diseases (Hendelman et al., 2000).

Obesity is a disease involving the over-accumulation of triglycerides, which cause such health problems as diabetes, arteriosclerotic heart disease, hypertension, etc. (Yaprak, 2004). Decrease in the physical activity level, and the accompanying decrease in the energy consumption altogether bring about obesity (Davies $e t$ al., 1997).

Researches conducted on its use in the treatment of obesity have shown that, regular physical activity is more effective in the slightly obese and overweight individuals than in the severely obese individuals. Numerous studies show that, regularly performed physical activity is an effective type of behavior in keeping the body weight at a normal level (Bouchard and Després, 1995).

Hypertension is a critical problem in terms of public health. Increased diastolic and systolic blood pressures pose risk for the development of such diseases as heart failure, coronary heart diseases, heart attack, and renal failure. According to the respectively conducted studies, regular stamina trainings with intensity of $40-60 \%$, that require maximum oxygen consumption, are effective in lowering the blood pressure. Besides, the habit of performing regular physical activity is recommended as a preventive method for avoiding the age-related increase in the blood pressure (Bouchard and Després, 1995).

Musculoskeletal health is described with four components. These are namely the muscle (mass, power, strength, and stability thereof), bone (mineral density and content of the bone), joints (quantity or flexibility of movements), and motor skills (coordination, balance, movement speed, and agility). Musculoskeletal components display a great deal of decrease as the one gets older. However the decrease in the mass, power, strength, and stability of the muscle is not solely age-related. Decrease in the habit of performing regular physical activity also gives rise to the same. Physical activity affects a number of the structural components of the musculoskeletal system positively. Physical activity plays a significant role in putting off and avoiding such musculoskeletal disorders as the mechanical waist ache, shoulder and neck aches, osteoporosis, and related fractures (Vuori, 1995).

Regularly performed physical activity causes not only increase in the high density level of lipoprotein cholesterol (HDL-C), but also decrease in the total cholesterol and low density level of lipoprotein cholesterol (LDL-C). It is suggested that, low plasma triglyceride, total cholesterol, LDL-C level, and increased HDL-C level generally lower the risk of the coronary heart diseases (Bouchard and Després, 1995).

While performing regular physical activity prevents catching numerous diseases, it also causes an increase in the physical capacity of the individuals. Furthermore, physical activity leads to an increase in the one's performance in his/her professional life, in his/her activities at home, and in his/her capacity to spend his/her free times. It has been ascertained that, in comparison to their sedentary peers, the ones performing regular physical activities have higher physical labor capacity values, and give faster muscular system reactions (Alpkaya and Mengütay, 2004).

In order to lay the foundations of a healthy society, alongside their educations, the children should be caused to adopt the habit of performing regular physical activity as early as possible. Scientific researchers pay great interest to assisting in the development of a healthy life style throughout the transition from childhood to adulthood, and to conducting studies regarding the determination of the habit of performing physical activity among the youth. For the children and the youth, the level of the motions being performed is as critical as the motion stimulations themselves regarding the benefit in their application to the children and the youth. Exercising in medium intensity has been found to be bringing in positive effect in the growth of the children (Iverson et al., 1985).

Increase in his/her physical capacity level shall not only increase the self-confidence of the individual, but also bring along positive contribution to his/her daily performance and productivity. It shall further increase the same individual's material and moral gains from the life. It may also be said that, regularly performed physical activities increase the life quality of their performers.

The purpose of this research is to determine the level of participation in the physical activities of the physical education and sports faculty students, and to examine their physical activity levels according to certain demographical features at hand. It sought answers to the following questions:

Among the physical education and sports faculty students:

- How are their physical activity levels?

- Is there any statistically meaningful difference found in their physical activity levels as per the gender variable?

- Is there any statistically meaningful difference found in their physical activity levels as per the age variable?

- Is there any statistically meaningful difference found in their physical activity levels as per the body mass index variable? 
- Is there any statistically meaningful difference found in their physical activity levels as per the monthly expenditure amount variable?

- Is there any statistically meaningful difference found in their physical activity levels as per the accommodation type variable?

- Is there any statistically meaningful difference found in their physical activity levels as per the attended faculty department variable?

- Is there any statistically meaningful difference found in their physical activity levels as per the sports branch variable?

- Is there any statistically meaningful difference found in their physical activity levels as per the smoking habit variable?

- Is there any statistically meaningful difference found in their physical activity levels as per the alcohol drinking variable?

\section{Material and Methods}

At this part of the research, the information regarding the population and sample groups, and the data collection tools, as well as the statistical processes used in the analysis of the data are included.

\subsection{The Population and Sample of the Study}

The population of the research consists of 480 students studying at the different programs of the Physical Education and Sports Faculty of Bozok University in the academic year of 2017-2018. The sample of the research consists of 300 students studying at the different programs of the Physical Education and Sports Faculty of Bozok University in the academic year of 2017-2018, who were respectively nominated by the convenience sampling method.

\subsection{Data Collection Tools}

In the research, while the demographical information regarding the students was attained by means of the personal information (gender, age, body mass index, monthly expenditure amount, accommodation type, attended faculty department, sports branch, smoking habit, and alcohol drinking) form, their levels of participation in the physical activities were attained by means of the International Physical Activity Questionnaire (IPAQ Short Form).

\section{Calculation and Value of the Body Mass Index}

Body Mass Index (BMI) is applicable to all age groups. In the calculation of the body mass index, the measured body height is converted from meter to centimeter, the attained figure is divided into the body weight in kilograms, and the attained result is compared with the standard values (Pekcan, 2008).

BMI = Body Weight $(\mathrm{kg}) /$ Body Height $\left(\mathrm{m}^{2}\right)$

Body Mass Index Values $\left(\mathrm{kg} / \mathrm{m}^{2}\right)$ (WHO, 1995)

- $18.5 \mathrm{~kg} / \mathrm{m}^{2}$ and lower Thin

- between $18.5-24.9 \mathrm{~kg} / \mathrm{m}^{2}$ Normal weighted

- between $25-29.9 \mathrm{~kg} / \mathrm{m}^{2}$ Over-weighted

- between $30-39.9 \mathrm{~kg} / \mathrm{m}^{2}$ Fat (Obese)

- above $40 \mathrm{~kg} / \mathrm{m}^{2}$ Excessively Fat (Morbid Obese)

For instance; while calculating the body mass index of a 20 years old person with body height of $170 \mathrm{~cm}$ and body weight of $65 \mathrm{~kg}$;

Body height in meter is $1.7 \mathrm{~m}$. Its Square is $1.7 \times 1.7=2.89$

$\mathrm{BMI}=65 / 2.89=22.49$. Consequently, the person in question has a normal BMI.

International physical activity scale

International Physical Activity Questionnaire (IPAQ) has been developed in order to determine the physical activity levels of the 15-69 years old persons (Craig et al., 2003). International Physical Activity Questionnaire (IPAQ) has been developed in short and long forms. In 1998 in Geneva, the studies to develop the IPAQ were commenced, and they were furthered by the reliability and validity studies respectively conducted at 14 research centers in 12 countries. As a result of the foregoing studies, it was declared that, IPAQ was a reliable and valid method to determine the physical activity (Atenz, 2001). The study on the reliability and validity of IPAQ in Turkey was conducted by Oztürk (2005) over the students studying at universities (Oztürk, 2005). The questionnaire consists of 4 different sections and a total of 7 questions. It is recommended to apply this questionnaire to adult persons within the age range of 15-69. The questionnaire involves questions regarding the physical activities having been performed for a duration of no shorter than 10 minutes in the last 7 days. It is determined by this questionnaire in how many days of the last week a) highly intense physical activities, b) fairly intense physical activities, and c) walking activities were performed, and for how long did such activities take per each day. In the last question, the time spent a day without moving (by sitting, lying, etc.) is determined. MET method was used in order to determine the physical activity level. Standard MET values were created for such activities. The MET values created are described as follows (Bozkuş et al., 2013)

- Intense Physical Activity = 8.0 MET

- Medium Physical Activity = 4.0 MET

- $\quad$ Walking $=3.3 \mathrm{MET}$

- $\quad$ Sitting = $1.5 \mathrm{MET}$

Daily and weekly physical activity levels are determined by means of these values. For instance; The MET$\mathrm{m} /$ week score for a person who walks for 30 minutes in 5 days of a week is calculated as $3.3 \times 5 \times 30=495$ MET$\mathrm{m} /$ week. 
IPAQ scoring directives and the physical activity classification criteria are indicated below (Ozüdoğru, 2013). Physical Activity Scoring Directive:

- Intense PA score $=8 \mathrm{x}$ (the number of days on which intense activity is performed) $\mathrm{x}$ (number of minutes per intense activity)

- Medium PA score $=8 \mathrm{x}$ (the number of days on which medium activity is performed) $\mathrm{x}$ (duration per medium activity in minutes)

- Walking PA score $=3.3 \mathrm{x}$ (number of days on which walking is performed) $\mathrm{x}$ (duration per walking activity in minutes)

- $\quad$ Total PA score = Intense PA score + Medium PA score + Walking PA score

- Physical Activity Classification Criteria:

- FA category at Inactive Level: Total PA score <600 MET-min./week

- FA category at Lower Level: 3000 MET-min./week > Total PA score $\geq 600$ MET min./week

- FA category at Adequate Level: Total PA score $\geq 3000$ MET-min./week

\subsection{Data Analysis}

For the resolution of the data attained as a result of the research, frequency and percentage analyses was applied in order to describe the demographical features of the participants, while cross tabulation, chi square test, and single direction variance analysis (ANOVA) were applied in order to assess the differences between the variances at hand.

\section{Findings}

This section includes the descriptive statistics and the findings regarding the discrimination tests.

Table 1 includes the findings regarding the students having answered the scale form.

According to Table 1, among the students having participated in the research, 129 (43\%) of them are females, and $171(57 \%)$ of them are males. While $52(17.3 \%)$ of these students are 18 years old, $90(30 \%)$ of them are 19 years old, $73(24.3 \%)$ of them are 20 years old, $44(14.7 \%)$ of them are 21 years old, $19(6.3 \%)$ of them are 22 years old, $12(4.0 \%)$ of them are 23 years old, $3(1.0 \%)$ of them are 24 years old, $5(1.7 \%)$ of them are 25 years old, $1(.3 \%)$ of them is 27 years old, and $1(.3 \%)$ of them is 30 years old. In view of the body mass indexes of the students, 21 $(7.0 \%)$ of them are classified as thin, $232(77.3 \%)$ of them are classified as normal weighted, $39(13.0 \%)$ of them are classified as over-weighted, and $8(2.7 \%)$ of them are classified as obese. In view of the amounts of the students' monthly expenditures, $125(41.7 \%)$ of them spend TL 500 or less, $69(23.0 \%)$ of them spend between TL 501 and TL $750,48(16.0 \%)$ of them spend between TL 751 and TL $1000,38(23.0 \%)$ of them spend between TL 1001 and TL 1250, and $20(6.7 \%)$ of them spend TL 1251 and above a month. While $9(3.0 \%)$ of them live alone in a house, $18(6.0 \%)$ of them live in a house with their families, $109(36.3 \%)$ of them live in a house with their friends, and 164 $(54.7 \%)$ of them live in a dormitory or apartment.

Table-1. Demographic features appertaining to the students

\begin{tabular}{|c|c|c|c|}
\hline & & $\mathbf{N}$ & $\%$ \\
\hline \multirow[t]{2}{*}{ Gender } & Female & 129 & 43.0 \\
\hline & Male & 171 & 57.0 \\
\hline \multirow[t]{10}{*}{ Age } & 18.00 & 52 & 17.3 \\
\hline & 19.00 & 90 & 30.0 \\
\hline & 20.00 & 73 & 24.3 \\
\hline & 21.00 & 44 & 14.7 \\
\hline & 22.00 & 19 & 6.3 \\
\hline & 23.00 & 12 & 4.0 \\
\hline & 24.00 & 3 & 1.0 \\
\hline & 25.00 & 5 & 1.7 \\
\hline & 27.00 & 1 & 3 \\
\hline & 30.00 & 1 & 3 \\
\hline \multirow[t]{4}{*}{ Body Mass Index } & $18.5 \mathrm{~kg} / \mathrm{m}^{2}$ and lower Thin & 21 & 7.0 \\
\hline & between $18.5-24.9 \mathrm{~kg} / \mathrm{m}^{2}$ Normal weighted & 232 & 77.3 \\
\hline & between $25-29.9 \mathrm{~kg} / \mathrm{m}^{2}$ Over-weighted & 39 & 13.0 \\
\hline & between $30-39.9 \mathrm{~kg} / \mathrm{m}^{2}$ Fat (Obese) & 8 & 2.7 \\
\hline \multirow[t]{5}{*}{ Monthly Expenditure Amount } & TL 500 and less & 125 & 41.7 \\
\hline & TL $501-$ TL 750 & 69 & 23.0 \\
\hline & TL $751-$ TL 1000 & 48 & 16.0 \\
\hline & TL 1001 - TL 1250 & 38 & 12.7 \\
\hline & TL 1251 and more & 20 & 6.7 \\
\hline \multirow[t]{4}{*}{ Accommodation Type } & Alone in a house & 9 & 3.0 \\
\hline & In a house together with his/her family & 18 & 6.0 \\
\hline & In a house together with his/her friends & 109 & 36.3 \\
\hline & In a dormitory or apartment & 164 & 54.7 \\
\hline \multirow[t]{3}{*}{ Attended Faculty Department } & Physical Education and Sports Teaching & 119 & 39.7 \\
\hline & Coaching Education & 128 & 42.7 \\
\hline & Sports Management & 53 & 17.7 \\
\hline \multirow[t]{3}{*}{ Sports Branch } & Individual Sports & 135 & 45.0 \\
\hline & Team Sports & 135 & 45.0 \\
\hline & $\mathrm{N} / \mathrm{A}$ & 30 & 10.0 \\
\hline \multirow[t]{2}{*}{ Smoking Habit } & Yes & 104 & 34.7 \\
\hline & No & 196 & 65.3 \\
\hline \multirow[t]{2}{*}{ Alcohol Drinking } & Yes & 47 & 15.7 \\
\hline & No & 253 & 84.3 \\
\hline
\end{tabular}


In view of the the faculty departments attended by the students, $119(39.7 \%)$ of them study at the physical education and sports teaching department, 128 (42.7\%) of them study at coaching education department, and 53 $(17.7 \%)$ of them study at sports management department. While $135(45.0 \%)$ of the students declared that they were occupied with individual sports, $135(45.0 \%)$ of them declared to be occupied with team sports, and $30(10.0 \%)$ of them declared to be occupied with no branch of sports. 104 (34.7\%) of the students declared to be smoking, 196 $(65.3 \%)$ of them declared to be non-smoking. In response to the question regarding alcohol drinking, $47(15.7 \%)$ of them answered yes, $253(84.3 \%)$ of them answered no.

Findings on the students' levels of participation to physical activities are given in Table 2.

Table-2. Findings on the students' levels of participation to physical activities

\begin{tabular}{l|l|l|l}
\hline \multicolumn{4}{c}{ Table-2. Findings on the students' levels of participation to physical activities } \\
\hline \\
\hline \multirow{3}{*}{ Physical Activity Level } & Inactive & $\mathbf{N}$ & $\%$ \\
\cline { 2 - 4 } & Lowly Active & 88 & 29.3 \\
\cline { 2 - 4 } & Adequately Active & 119 & 39.7 \\
\cline { 2 - 4 } & Total & 300 & 31.0 \\
\hline
\end{tabular}

According to the Table 2, while 119 (39.7\%) of the students are at lowly active level, $93(31.0 \%)$ thereof are found to display participation to the physical activities at adequately active level.

In the Table 3, the findings regarding the comparison of physical activity level as per gender are shown.

Table-3. The chi-square findings regarding the comparison of physical activity level as per gender

\begin{tabular}{|c|c|c|c|c|}
\hline & & \multicolumn{2}{|l|}{ Gender } & \multirow[b]{2}{*}{ Total } \\
\hline & & Female & Male & \\
\hline \multirow{3}{*}{ Physical Activity Level } & Inactive & 43 & 45 & 88 \\
\hline & Lowly Active & 56 & 63 & 119 \\
\hline & Adequately Active & 30 & 63 & 93 \\
\hline \multicolumn{2}{|l|}{ Total } & 129 & 171 & 300 \\
\hline
\end{tabular}

According to the Table 3, a statistically meaningful difference $(\mathrm{p}<.05)$ has been found as a result of the physical activity comparison as per the gender variance. While 30 of the female students show participation to physical activities at adequately active level, the same level of participation to physical activities is shown by 63 of the male students. Male students have been found to be active at a level higher than that of the female students.

In the Table 4, the findings regarding the comparison of physical activity level as per age are shown.

Table-4. ANOVA findings regarding the comparison of physical activity level as per age

\begin{tabular}{l|l|l|l}
\hline & $\mathbf{d f}$ & $\mathbf{F}$ & $\mathbf{p}$ \\
\hline Between Groups & 9 & \multirow{2}{*}{.908} & \multirow{2}{*}{.519} \\
\hline Within Group & 290 & & \\
\hline Total & 299 & & \\
\hline $\mathrm{p}<.05 ;{ }^{* *} \mathrm{p}<.001$ & &
\end{tabular}

According to the Table 4, a statistically meaningful difference ( $\mathrm{p}>.05)$ has not been found as a result of the physical activity comparison as per the age variance. shown.

In the Table 5, the findings regarding the comparison of physical activity level as per body mass index are

Table-5. The chi-square findings regarding the comparison of physical activity level as per body mass index

\begin{tabular}{|c|c|c|c|c|c|c|}
\hline & & \multicolumn{4}{|c|}{ Body Mass Index } & \multirow[b]{2}{*}{ Total } \\
\hline & & \begin{tabular}{|l|}
$\begin{array}{l}18.5 \\
\mathrm{~kg} / \mathrm{m}^{2} \quad \text { and } \\
\text { lower Thin } \\
\text { Thin }\end{array}$ \\
\end{tabular} & $\begin{array}{l}\text { between 18.5- } \\
24.9 \mathrm{~kg} / \mathrm{m}^{2} \\
\text { Normal } \\
\text { Weighted }\end{array}$ & \begin{tabular}{|l} 
between $\quad 25-$ \\
$29.9 \quad \mathrm{~kg} / \mathrm{m}^{2}$ \\
Over- \\
Weighted \\
\end{tabular} & $\begin{array}{l}\text { between30-39.9 } \\
\mathrm{kg} / \mathrm{m}^{2} \text { Obese(Fat) }\end{array}$ & \\
\hline \multirow{3}{*}{$\begin{array}{l}\text { Physical Activity } \\
\text { Level }\end{array}$} & Inactive & \begin{tabular}{|l|}
7 \\
\end{tabular} & 59 & 15 & 7 & 88 \\
\hline & Lowly Active & 12 & 91 & 15 & 1 & 119 \\
\hline & $\begin{array}{l}\text { Adequately } \\
\text { Active }\end{array}$ & 2 & 82 & 9 & $\mathrm{O}$ & 93 \\
\hline Total & & 21 & 232 & 39 & 8 & 300 \\
\hline
\end{tabular}

$\mathrm{X}^{2}=22.59 ; \mathrm{df}=6 ; \mathrm{p}=.001$

According to the Table 5, a statistically meaningful difference $(\mathrm{p}<.05)$ has been found as a result of the physical activity comparison as per the body mass index variance. A great majority of the students have been determined as normal weighted $(n=232)$. A great majority of the normal weighted students have further been found as being lowly active $(n=91)$ or adequately active $(n=82)$.

The chi-square findings regarding the comparison of physical activity level as per monthly expenditure amount have been shown in Table 6. 
Table-6. The chi-square findings regarding the comparison of physical activity level as per monthly expenditure amount

\begin{tabular}{|c|c|c|c|c|c|c|c|}
\hline & \multicolumn{5}{|c|}{ Monthly Expenditure Amount } & \multirow[b]{2}{*}{ Total } \\
\hline & & TL 500 and less & TL 501- TL 750 & TL 751 - TL 1000 & TL 1001 - TL 1250 & $\begin{array}{l}\text { TL } 1251 \text { and } \\
\text { more }\end{array}$ & \\
\hline \multirow{3}{*}{$\begin{array}{l}\text { Physical } \\
\text { Activity Leve }\end{array}$} & Inactive & \begin{tabular}{|l|}
31 \\
\end{tabular} & 25 & 9 & \begin{tabular}{|l|}
14 \\
\end{tabular} & 9 & 88 \\
\hline & Lowly Active & 58 & 21 & 20 & 16 & 4 & 119 \\
\hline & Adequately Active & 36 & 23 & 19 & 8 & 7 & 93 \\
\hline Total & & 125 & 69 & 48 & 38 & 20 & 300 \\
\hline
\end{tabular}

$\mathrm{X}^{2}=13.97 ; \mathrm{df}=8 ; \mathrm{p}=.082$

According to the Table 6, a statistically meaningful difference ( $\mathrm{p}>.05)$ has not been found as a result of the physical activity comparison as per the monthly expenditure amount variance.

In the Table 7, the findings regarding the comparison of physical activity level as per accommodation type are shown.

Table-7. The chi-square findings regarding the comparison of physical activity level as per accommodation type

\begin{tabular}{|c|c|c|c|c|c|c|}
\hline & & \multicolumn{4}{|c|}{ Accommodation Type } & \multirow[b]{2}{*}{ Total } \\
\hline & & $\begin{array}{l}\text { Alone in } \\
\text { house }\end{array}$ & \begin{tabular}{|l|l|} 
In $\quad$ a & house \\
together & with \\
his/her family
\end{tabular} & $\begin{array}{l}\text { In a house together } \\
\text { with his/her friends }\end{array}$ & $\begin{array}{l}\text { In a dormitory } \\
\text { or apartment }\end{array}$ & \\
\hline \multirow{3}{*}{$\begin{array}{l}\text { Physical } \\
\text { Activity } \\
\text { Level }\end{array}$} & Inactive & 3 & 4 & 29 & 52 & 88 \\
\hline & Lowly Active & 1 & 9 & 45 & 64 & 119 \\
\hline & $\begin{array}{l}\text { Adequately } \\
\text { Active }\end{array}$ & 5 & 5 & 35 & 48 & 93 \\
\hline Total & & 9 & 18 & 109 & 164 & 300 \\
\hline
\end{tabular}

$\mathrm{X}^{2}=5.38 ; \mathrm{df}=6 ; \mathrm{p}=.495$

According to the Table 7 , a statistically meaningful difference ( $p>.05)$ has not been found as a result of the physical activity comparison as per the accommodation type variance.

In the Table 8, the findings regarding the comparison of physical activity level as per attended department of faculty are shown.

Table-8. The chi-square findings regarding the comparison of physical activity level as per attended faculty of department

\begin{tabular}{|c|c|c|c|c|c|}
\hline & & \multicolumn{3}{|c|}{ Attended Faculty Department } & \multirow[b]{2}{*}{ Total } \\
\hline & & $\begin{array}{l}\text { Physical Education and } \\
\text { Sports Teaching }\end{array}$ & $\begin{array}{l}\text { Coaching } \\
\text { Education }\end{array}$ & \begin{tabular}{|l|} 
Sports \\
Management \\
\end{tabular} & \\
\hline \multirow{3}{*}{$\begin{array}{l}\text { Physical } \\
\text { Activity Level }\end{array}$} & Inactive & 33 & 41 & 14 & 88 \\
\hline & Lowly Active & 43 & 45 & 31 & 119 \\
\hline & Adequately Active & 43 & 42 & 8 & 93 \\
\hline \multicolumn{2}{|l|}{ Total } & 119 & 128 & 53 & 300 \\
\hline
\end{tabular}

$\mathrm{X}^{2}=11.81 ; \mathrm{df}=4 ; \mathrm{p}=.019$

According to the Table 8 , a statistically meaningful difference $(\mathrm{p}<.05)$ has been found as a result of the physical activity comparison as per the attended faculty department variance. The students from the physical education and sports teaching $(n=43)$ and the coaching education $(n=42)$ departments have been found to have displayed adequate levels of participation to the physical activities in comparison to those of the students from the sports management department.

In the Table 9, the findings regarding the comparison of physical activity level as per sports branch are shown.

Table-9. The chi-square findings regarding the comparison of physical activity level as per sports branch

\begin{tabular}{|c|c|c|c|c|c|}
\hline & & \multicolumn{3}{|c|}{ Sports Branch } & \multirow[b]{2}{*}{ Total } \\
\hline & & Individual & Team & $\mathbf{N} / \mathbf{A}$ & \\
\hline \multirow[t]{3}{*}{ Physical Activity Level } & Inactive & 45 & 33 & 10 & 88 \\
\hline & Lowly Active & 54 & 49 & 16 & 119 \\
\hline & Adequately Active & 36 & 53 & 4 & 93 \\
\hline \multicolumn{2}{|l|}{ Total } & 135 & 135 & 30 & 300 \\
\hline
\end{tabular}

According to the Table 9, a statistically meaningful difference $(\mathrm{p}<.05)$ has been found as a result of the physical activity comparison as per the sports branch variance. It has been ascertained that, a great majority $(\mathrm{n}=53)$ of the ones having displayed adequate level of participation to the physical activities are occupied with team sports.

In the Table 10, the findings regarding the comparison of physical activity level as per smoking habit are shown.

Table-10. The chi-square findings regarding the comparison of physical activity level as per smoking habit

\begin{tabular}{|c|c|c|c|c|}
\hline & & \multicolumn{2}{|c|}{ Smoking Habit } & \multirow[b]{2}{*}{ Total } \\
\hline & & Yes & No & \\
\hline \multirow{3}{*}{ Physical Activity Level } & Inactive & 29 & 59 & 88 \\
\hline & Lowly Active & 52 & 67 & 119 \\
\hline & Adequately Active & 23 & 70 & 93 \\
\hline \multicolumn{2}{|l|}{ Total } & 104 & 196 & 300 \\
\hline
\end{tabular}


According to the Table 10, a statistically meaningful difference $(\mathrm{p}<.05)$ has been found as a result of the physical activity comparison as per the smoking habit variance. It has been ascertained that, a great majority $(n=70)$ of the non-smoking have displayed adequate level of participation to the physical activities.

In the Table 11, the findings regarding the comparison of physical activity level as per alcohol drinking are shown.

Table-11. The chi-square findings regarding the comparison of physical activity level as per alcohol drinking

\begin{tabular}{|c|c|c|c|c|}
\hline & & \multicolumn{2}{|c|}{ Alcohol Drinking } & \multirow[b]{2}{*}{ Total } \\
\hline & & Yes & No & \\
\hline \multirow[t]{3}{*}{ Physical Activity Level } & Inactive & 14 & 74 & 88 \\
\hline & Lowly Active & 19 & 100 & 119 \\
\hline & Adequately Active & 14 & 79 & 93 \\
\hline \multicolumn{2}{|l|}{ Total } & 47 & 253 & 300 \\
\hline
\end{tabular}

$\mathrm{X}^{2}=.38 ; \mathrm{df}=2 ; \mathrm{p}=.981$

According to the Table 11, a statistically meaningful difference ( $\mathrm{p}>.05)$ has not been found as a result of the physical activity comparison as per the alcohol drinking variance.

\section{Discussion}

In this research intended to determine whether there is any difference in the physical activity levels of the students studying at different departments of the physical education and sports faculties according to certain demographical features (gender, age, body mass index, monthly expenditure amount, accommodation type, attended faculty department, sports branch, smoking habit, and alcohol drinking) at hand, the following results have been attained:

In view of the physical activity levels of the students studying at different departments of the physical education and sports faculties, while 119 of them have been found as displaying lower levels of participation to the physical activities, and 93 of them as displaying adequate levels, 88 of them have been found to be physically inactive. According to this conclusion reached in the research, it may be said that, despite a great majority of the students have lower levels of physical activity, a significant majority of the same display adequate level of participation to the physical activities. Although there are applied courses in the curriculums of the physical education and sports faculty students, alongside lack of the establishment facilities and opportunities within the developing campuses, it is suggested that, the increase in the technological environments within the houses, dormitories, apartments, and other locations have restricted the students' adequate participation to the physical activities. Similar conclusions have been reached in the researches conducted by Olçücü et al. (2015) and Savcl et al. (2006).

A statistically meaningful difference $\left(\mathrm{X}^{2}=6.41 ; \mathrm{p}<.05\right)$ has been attained between the gender variable and physical activity level. Male students display higher levels of participation to the physical activities than the female students. It is suggested that, while the male students intensely take part in the individual and team sports, where they are more dominant over the physiological and biological impacts of the physical activity, the female students are found to participate in the physical activities so as to remain healthy, fit, and strong. There are also a number of studies available in the literature, revealing the fact that, the physical activity levels of the males are higher than those of the females. The researchers conducted by Stephens et al. (1985); King et al. (1992); Adams et al. (1992); Riddoch and Boreham (1995); Myers et al. (1996); Leslie et al. (1999); Crocker and Faulkner (1999); Trost et al. (2002); Yıldırım and Bayrak (2017); Olçücü et al. (2015); Polat and Simşek Yıldırım (2015); Baş et al. (2007); Kızar et al. (2016); Kara (2006) have also yielded conclusions similarly indicating that the male students' levels of participation to the physical activities are meaningfully higher than those of the female students. The results attained from this research show similarity with the findings attained from the foregoing researches.

A statistically meaningful difference $\left(\mathrm{X}^{2}=22.59 ; \mathrm{p}<.05\right)$ has been attained between the body mass variable and physical activity level. As a result of the body mass calculations, the ones with normal weights have higher levels of participation to the physical activities than those of the light weighted and obese ones. In terms of health and performance, it is suggested that, while the students having performed the intensive activities among the sports activities could have kept their physical structures, the light weighted ones liked the appearances of their bodies, and felt no need for further physical activities. Similar suggestions were raised in the researches conducted by Nordqvist (2003); Memiş and Yildıran (2007). In the study conducted by Yancey et al. (2004) no statistically meaningful relation could have been ascertained between being sedentary and body mass index.

A statistically meaningful difference $\left(\mathrm{X}^{2}=11.81 ; \mathrm{p}<.019\right)$ has been attained between the department variable and physical activity level. It has been ascertained that, the students from the physical education and sports teaching and the trainer education departments tend to display higher levels of participation to the physical activities than those of the sports management department students. Such a result is suggested to arise from the facts that, while the students of physical education and sports teaching and the trainer education departments are admitted to their departments by way of special talent test, the sports management department students are admitted to their department upon their respective choices for the student placement examination, and that the students of the physical education and sports teaching and the trainer education departments tend to take part in the sports activities more in their past years. Besides, the curriculums of the physical education and sports teaching and the trainer education departments differ from that of the sports management department. The sports management department students are taught more intensely with theoretical courses than the applied ones. This may also be considered as a situation that affects the participation of the sports management department students to the physical activities. No statistically meaningful difference could have been found in the study conducted by Aydin and Solmaz (2016) among the students studying at the different departments of the faculty of sports sciences. There is an apparent difference with this study. 
In the research, a statistically meaningful difference $\left(\mathrm{X}^{2}=10.61 ; \mathrm{p}=.031\right)$ has been found as a result of the comparison of the physical activity level as per the sports branch variable. The ones who are occupied in individual and team sports tend to have higher levels of participation to the physical activities than those of the ones without any branch. It is suggested that, the ones who are occupied in individual and team sports are to be the students of the physical education and sports teaching and the trainer education departments, and those without any branch are to be the sports management department students. The activity levels of the students who are taking applied courses, and occupied with individual and team sports within sports clubs have naturally been found to be higher.

In the research, a statistically meaningful difference $\left(\mathrm{X}^{2}=8.45 ; \mathrm{p}=.015\right)$ has been found as a result of the comparison of the physical activity level as per the smoking habit variable. It has been determined that, the ones who do not smoke have higher levels of participation to the physical activities than those of the ones who do smoke. Smoking, even 1 cigarette per day, may have an immediate impact on the one's exercising capacity. Stamina capacity of the ones who smoke is lower than that of the ones who do not smoke. In terms of health, the smokers tend to participate less in the physical activities. The youth smokers experience the same negative effects being experienced by the adult smokers. Physical endurance and performance of the smokers is lower than that of their peers who do not smoke. Besides, the feeling of breathlessness, increase in the sports injuries, and deterioration of general health are the problems that are encountered frequently (Sağlam et al., 2008). It is suggested that, among both youth and adult smokers, the conditions of the ones who give up smoking may be restored to normal. In the study that was conducted by Arabacı and Cankaya (2007) with the intent of "investigating the physical activity levels of the physical education teachers" on the basis of the consideration that the ones who smoke have lower physical activity levels than those of the ones who do not smoke, it is concluded that, the ones who do not smoke tend to have higher physical activity levels than those of the smokers. It was shown in the studies conducted by Burton and Turrell (2000); Topsaç and Bişgin (2014) that, the smokers are inactive persons. The results attained from these studies are similar to those attained from this study. In the study conducted by Aydin and Solmaz (2016) among the students of the faculty of sports sciences, however, no statistically meaningful difference could have been found between the smoking and non-smoking students in terms of their levels of participation to the physical activities. This contradicts with the respective results of this study.

Regularly performed physical activities shall not only lead the person to think positively, but also have positive physical, psychological, and social impacts on the same person. Furthermore, the ones who regularly perform activities shall experience increase in their life quality, and shall also become self-confident, determined, and successful individuals, who are capable of applying auto-control on themselves thanks to their more balanced personalities. It is also suggested that, performing medium level of physical activity is the best way to get away from the negative impacts of a stressful life.

The following recommendations are put forth in parallel with the findings attained from this study.

- Elimination of the factors that impede participation to physical activity requires focusing on studies intended for increasing the levels of participation to physical activity of the students coming from varying socio-economical and cultural backgrounds.

- In this research, it has been ascertained that, the male students have higher levels of participation to the physical activities than those of the female students. In order to increase the activity levels of the female students, their sports preferences should be identified, and they should be encouraged to show participation in the respective directions.

- Performing physical activity regularly shall be helpful in keeping the one's ideal body weight. For this purpose, the persons who are inactive and active at lower levels should be informed with respect to body mass index.

- It has been found in this research that, the students of the physical education and sports teaching and the trainer education departments have levels of participation to physical activities higher than those of the sports management department students. Revision of the curriculums of the sports management department, and increasing the number of hours of the applied courses therein shall cause the students of this department also participate in the activities intensively.

- The students who perform their branches at top level should be offered with physical, material, and moral opportunities in order to maintain their persistence in their university lives. Furthermore, the works for sports facilities and organizations within the campus areas should be intensified so as to enable the students spend their spare times within sports activities.

- Physical activity is helpful in eliminating the smoking habit, and for the smokers to quit smoking. Above all, regularly performed physical activity facilitates the elimination of the symptoms caused by smoking in shorter times, and particularly declines the risk of such chronic diseases as heart diseases and cancer. Both adult and youth smokers may restore to positive conditions if they are to quit smoking. In this respect the children and the youth should be undergone relevant detailed informative studies.

\section{References}

Adams, P., C.A. Schoenborn, A.J. Moss, C.W. Warren and L. Kann, 1992. Health-risk behaviors among our nation's youth: United States. Hyattsville, MD: U.S. Department of Health and Human Services, Public Health Service.

Alpkaya, U. and S. Mengütay, 2004. Investigation of reaction period of physical activity. Journal of Gazi Physical Education and Sport Sciences, 9(3): 49-57.

Arabacı, R. and C. Cankaya, 2007. Investigation of physical activity levels of physical education teachers. Education Faculty Magazine, 20(1): $1-15$.

Atenz, A., 2001. A review of empirically based physical activity program formiddle aged toolder adults. Journal of Aging and Physical Activity, 9(1): 38-55.

Aydın, G. and Y.D. Solmaz, 2016. The physical activity levels of the students at the school of sports sciences. Journal of İnönü University Physical Education and Sports Sciences, 3(1): 34-46.

Baş, A.U., A. Livanelioğlu and Ş. Aslan, 2007. Evaluation of physical activity level in university students with two different methods. Journal of Turkish Physiotherapy and Rehabilitation, 18(1): 11-19.

Bek, N., 2008. Physical activity and health, physical activity information series. Ankara: Ministry of Health Publications. 
Bouchard, C. and J.-P. Després, 1995. Physical activity and health: Atherosclerotic, metabolic, and hypertensive diseases. Research Quarterly for Exercise and Sport, 66(4): 268-275.Available at: https://doi.org/10.1080/02701367.1995.10607911.

Bozkuş, T., M. Türkmen, M. Kul, A. Özkan, Ü. Öz and C. Cengiz, 2013. Determining and associating the physical activity levels and healthy lifestyle behaviors of the students in the school of physical education and sports. International Journal of Science Culture and Sport, 1(3): 49-65.

Burton, N.W. and G. Turrell, 2000. Occupation, hours worked, and leisure-time physical activity. Preventive Medicine, 31(6): 673681.Available at: https://doi.org/10.1006/pmed.2000.0763.

Craig, C.L., A.L. Marshall, M. Sjorstrom, A.E. Bauman, M.L. Booth, B.E. Ainsworth, M. Pratt, U. Ekelund, A. Yngve and J.F. Sallis, 2003. International physical activity questionnaire: 12-country reliability and validity. Medicine and Science in Sports and Exercise, 35(8): 1381-1395.Available at: https://doi.org/10.1249/01.mss.0000078923.96621.1d.

Crocker, P.R.E. and R. Faulkner, 1999. Self-report of physical activity intensity in youth: Gender and grade level considerations. AvanteGloucester Ontario, 5(3): 43-51.

Davies, P.S.W., J.-Y. Feng, J.A. Crisp, J.M. Day, A. Laidlaw, J. Chen and X.-P. Liu, 1997. Total energy expenditure and physical activity in young Chinese gymnasts. Pediatric Exercise Science, 9(3): 243-252.Available at: https://doi.org/10.1 123/pes.9.3.243.

Gür, H. and S. Küçükoğlu, 1992. Aging and physical activity. İstanbul: Roche Publishing.

Hendelman, D., K. Miller, C. Baggett, E. Debold and P. Freedson, 2000. Validity of accelerometry for the assessment of moderate intensity physical activity in the field. Medicine and Science in Sports and Exercise, 32(9 Suppl): S442-S449.Available at: https://doi.org/10.1097/00005768-200009001-00002.

Howley, E.T., 2001. Type of activity: Resistance, aerobic and leisure versus occupational physical activity. Medicine \& Science in Sports \& Exercise, 33(6): S364-S369.Available at: https://doi.org/10.1097/00005768-200106001-00005.

Iverson, D.C., J.E. Fielding, R.S. Crow and G.M. Christenson, 1985. The promotion of physical activity in the United States population: The status of programs in medical, worksite, community, and school settings. Public Health Reports, 100(2): 212-224.

Kara, D., 2006. An Investigation of socio-economic factors in population dissemination of sports (Sample of Niğde City). Unpublished Master's Thesis, Niğde Üniversity Institute of Social Sciences, Niğde.

King, A.C., S.N. Blair, D.E. Bild, R.K. Dishman, P.M. Dubbert, B.H. Marcus, N.B. Oldridge, R.S. Paffenbarger, K.E. Powell and K.K. Yeager, 1992. Determinants of physical activity and interventions in adults. Medicine \& Science in Sports \& Exercise, 24(6 Suppl): 22 1-236.

Kızar, O., M. Kargün, T.O. Togo, M. Biner and A. Pala, 2016. Examination of physical activity levels of university students Journal of Marmara University Sport Sciences, 1(1): 61-72

Leslie, E., N. Owen, J. Salmon, A. Bauman, J.F. Sallis and S.K. Lo, 1999. Insufficiently active Australian college students: Perceived personal, social, and environmental influences. Preventive Medicine, 28(1): 20-27.Available at: https://doi.org/10.1006/pmed.1998.0375.

Memiş, A.U. and İ. Yıldıran, 2007. Determination of physical activity levels of instructors according to some variables Journal of Gazi Physical Education and Sport Sciences, 12(3): 11-24.

Myers, L., P.K. Strikmiller, L.S. Webber and G.S. Berenson, 1996. Physical and sedentary activity in school children grades 5-8: The Bogalusa heart study. Medicine and Science in Sports and Exercise, 28(7): 852-859.Available at: https://doi.org/10.1097/00005768-199607000-00012.

Nordqvist, D., 2003. Physical activity levels in children and youth. The Degree of Master of Science, Dalhousie University.

Olçücü, B., Ş. Vatansever, G. Özcan, A. Celik and Y. Paktaş, 2015. The relationship between physical activity level and depression and anxiety in university students. International Journal of Turkish Educational Sciences, 3(4): 294-303.

Oztürk, M., 2005. A research on reliability and validity of international physical activity questionnaire and determination of physical activity level in university students. Hacettepe University Health Science Institute an Unpublished PhD Thesis, Ankara (in Turkish).

Ozüdoğru, E., 2013. Investigation of the relationship between physical activity level and quality of life of university staff. Unpublished Master's Thesis Mehmet Akif Ersoy University Institute of Educational Sciences, Burdur.

Pekcan, G., 2008. Determination of nutrition status. Ankara: Ministry of Health Publications.

Polat, C. and K. Simşek Yıldırım, 2015. The study of individuals' exercise addiction levels at sports centres: Eskişehir sample. The Journal of Academic Social Science 3(15): 354-369.

Riddoch, C.J. and C.A.G. Boreham, 1995. The health-related physical activity of children. Sports Medicine, 19(2): 86-102.Available at: https://doi.org/10.2 165/00007256-199519020-00002.

Sağlam, M., B.M. Güçlü, İ.D. Ince, S. Savcı and H. Arıkan, 2008. Smoking and physical activity. Ankara: Ministry of Health Publications.

Savcı, S., M. Oztürk, H. Arıkan, D. Inal İnce and L. Tokgözoğlu, 2006. Physical activity levels of university students. Archives of the Turkish Society of Cardiology, 34(3): 166-172.

Stephens, T., D.R. Jacobs Jr and C.C. White, 1985. A descriptive epidemiology of leisure-time physical activity. Public Health Reports, $100(2): 147-158$.

Topsaç, M. and H. Bişgin, 2014. Examination of physical activity levels of disabled students reading in university. Dumlupınar Üniversity Journal of Social Science, $40(1): 163-174$.

Trost, S.G., R.R. Pate, J.F. Sallis, P.S. Freedson, W.C. Taylor, M. Dowda and J. Sirard, 2002. Age and gender differences in objectively measured physical activity in youth. Medicine \& Science in Sports \& Exercise, 34(2): 350-355.Available at: https://doi.org/10.1097/00005768-200202000-00025.

Vuori, I., 1995. Exercise and physical health: Musculoskeletal health and functional capabilities. Research Quarterly for Exercise and Sport, 66(4): 276-285.Available at: https://doi.org/10.1080/02701367.1995.10607912.

WHO, 1995. Physical status: The use and interpretation of anthropometry. WHO Technical Report Series 854, Geneva.

Yancey, A.K., C.M. World, W.J. Mccarthy, M.D. Weber, B. Lee, P.A. Simon and J.E. Fielding, 2004. Physical inactivity and overwight among Los Angeles county adults. American Journal Preventive Medicine, 27(2): 146-152.Available at: https://doi.org/10.1016/j.amepre.2004.03.012.

Yaprak, Y., 2004. Effects of aerobic and force work on oxygen utilization and heart failure in obese women, sportmeter Journal of Physical Education and Sports Sciences, 2(2): 73-80.

Yıldırım, M. and C. Bayrak, 2017. Determination of participation levels of physical activities of university students accordıng to demographic characteristics (Sample of Eskişehir Osmangazi University). The Journal of Academic Social Science, 5(54): 310-330. 